\title{
A (RE)INVENÇÃO DE SI ATRAVÉS DAS NARRATIVAS AUTOBIOGRÁFICAS
}

\author{
Marcio Santos da Conceição ${ }^{1}$
}

\begin{abstract}
Resumo: A presente pesquisa tem como objetivo mostrar de que forma as narrativas autobiográficas permitem uma reflexão acerca da formação e da prática docente. Do ponto de vista metodológico foi desenvolvida uma pesquisa de natureza qualitativa através do método autobiográfico em forma de pesquisa narrativa com base em entrevistas, e uma análise crítica dos dados à luz da crítica cultural. A fundamentação teórica baseou-se em autores da Crítica Cultural, e alguns que discutem a correlação entre autobiografia e educação, tais como: Josso (2008), Souza (2006), Foucault (2010), Nóvoa (2004), Tardif (2006), Agamben (2008), Derrida (1990), Deleuze (2004), Guattari (2004), entre outros. Através da pesquisa autobiográfica pode-se identificar a representação social da professora sobre a sua profissão assim como entender os sentidos que a docência assume para ela, em articulação com diferentes dimensões de sua vida. Dentro dessa articulação, pode-se constatar que essas narrativas contribuem para a valorização da identidade do professor, evidenciam a importância da subjetividade no seu processo formativo, contrapondo-se a um modelo cartesiano de formação, onde, muitas vezes, o ser professor é visto como um mero transmissor do conhecimento construído por outros; percebemos também que a escola ainda permanece como um lugar onde as diferenças não são respeitadas, onde as representações sociais de gênero, raça, são internalizadas desde muito cedo e legitimadas por ideologias racistas e patriarcais.
\end{abstract}

Palavras-chave: Estudos Culturais. Narrativas autobiográficas. Representações Sociais.

\section{A (RE) INVENTION OF THROUGH AUTOBIOGRAPHIC NARRATIVES}

\begin{abstract}
The present research aims to show how the autobiographical narratives allow a reflection about the formation and the teaching practice. From the methodological point of view, a qualitative research was developed through the autobiographical method in the form of narrative research based on interviews, and a critical analysis of the data in the light of cultural criticism. The theoretical foundation was based on authors of Cultural Criticism, and some who discuss the correlation between autobiography and

\footnotetext{
${ }^{1}$ Mestre em Letras pelo Programa de Pós-Graduação em Crítica Cultural da Universidade do Estado da Bahia, Campus II - Alagoinhas-BA, Mestre em Teologia pela Escola Superior de Teologia do Rio Grande do Sul, Especialista em Estudos Linguísticos e Literários e Graduado em Letras-Francês pela Universidade do Estado da Bahia. Contato: msconceicao18@gmail.com.
} 
education, such as: Josso (2008), Souza (2006), Foucault (2010), Nóvoa (2004), Tardif , Agamben (2008), Derrida (1990), Deleuze (2004), Guattari (2004), among others. Through the autobiographical research one can identify the social representation of the teacher about her profession as well as understand the meanings that teaching assumes for her, in articulation with different dimensions of her life. Within this articulation, it can be seen that these narratives contribute to the valorization of the teacher's identity, evidence the importance of the subjectivity in its formative process, in opposition to a Cartesian model of formation, where, often, being a teacher is seen as a mere transmitter of knowledge constructed by others; we also perceive that the school still remains a place where differences are not respected, where the social representations of gender, race, are internalized from a very early age and legitimized by racist and patriarchal ideologies.

Keywords: Cultural Studies. Autobiographical narratives. Social Representations.

\section{Introdução}

A pesquisa aqui apresentada está vinculada à minha dissertação de mestrado intitulada Narrativas autobiográficas de uma professora negra quilombola: espaço de ressignificação do ser e do fazer docente, defendida em dezembro de 2018, porém que nasceu de reflexões acerca da formação docente iniciadas durante o período de formação na Especialização em Estudos Linguísticos e Literários que terminei ao final de 2010. Pensar a formação docente a partir das narrativas de professores foi uma descoberta que me abriu novos horizontes no mundo da pesquisa e veio ao encontro de algumas inquietações que me habitavam desde o período da minha graduação em Letras pela Universidade do Estado da Bahia, em Alagoinhas.

A proposta do Grupo de Estudos em Educação, Resiliência e Linguagens - GEREL, do qual sou membro desde aquele período, foi fazer uma correlação entre as narrativas autobiográficas, as histórias de vida e a formação docente. Daí num primeiro momento comecei a pesquisar sobre as histórias de vida de duas professoras da zona rural do Oiteiro, distrito da Cidade de Alagoinhas-BA, visando entender de que forma as narrativas de professoras negras de uma comunidade rural e quilombola referentes ao seu itinerário escolar influenciavam e norteavam sua prática pedagógica? 
A pesquisa tinha uma preocupação em discutir a formação docente e trazer o diferencial que o estudo das narrativas de vida de educadores em diferentes espaços educacionais no Brasil, tem trazido no campo da formação nesses últimos anos. Constatamos, com base nos teóricos referenciados na pesquisa, que as narrativas contribuem para a valorização da identidade do professor, evidenciam a importância da subjetividade no seu processo formativo, contrapondo-se a um modelo cartesiano de formação, onde, muitas vezes, o ser professor é visto como um mero transmissor do conhecimento construído por outros.

Nos últimos vinte anos, há uma grande preocupação centrada nas habilidades e nas competências dos educadores. Segundo Souza (2006, p. 34) "colocar a pessoa do professor como uma das centralidades do projeto formativo é fundamental, na medida em que permite entender o significado do desenvolvimento pessoal no processo profissional do trabalho docente".

No que se refere à formação e à identidade de professores, Elizeu Clementino de Souza nos fala de uma crise que estamos vivendo. Citando Nóvoa, o autor nos diz que:

[...] a racionalidade técnica impôs uma separação entre o eu profissional do eu pessoal. A transposição dessa atitude do plano científico para o plano institucional contribuiu para intensificar o controle sobre os professores, favorecendo o seu processo de desprofissionalização (SOUZA, 2006, p. 34).

A importância da formação docente advém da compreensão que, à medida que os professores são tratados como sujeitos da sua formação e não como meros transmissores do conhecimento, a sua prática tornar-se-á mais consequente. Foi a partir daí que se pode traçar de maneira mais clara a estrutura da pesquisa que pretendia analisar de que forma aquilo que somos e fazemos em sala de aula está ligado àquilo que vivenciamos no decorrer das nossas experiências dentro e fora dos ambientes formais da escola.

Esta primeira pesquisa foi ampliada e tornou-se a base para uma segunda pesquisa com as narrativas autobiográficas que foi desenvolvida no Mestrado em Letras - Crítica Cultural no Departamento de Educação do Campus II da UNEB em Alagoinhas que deu origem ao trabalho supracitado que acrescentava dois elementos novos na investigação: os estudos étnicosraciais por conta da Educação Quilombola à qual não demos tanta ênfase na 
pesquisa anterior, e a Teoria das Representações Sociais, partindo ainda da perspectiva dos Estudos Culturais.

\section{A abordagem autobiográfica e os estudos culturais}

As experiências com a abordagem (auto)biográfica na formação docente têm recebido contribuições fundamentais de Josso (2008) de Souza (2006) e de Nóvoa (2004) entre outros, que defendem que, através da abordagem biográfica o sujeito produz um conhecimento sobre si, sobre os outros e o cotidiano, o qual se revela através da subjetividade, da singularidade das experiências e dos saberes. Através dessa abordagem, podemos compreender que a formação é um processo que não se dá de forma linear e que não é somente dentro do mundo acadêmico que os saberes dos professores são construídos e sim através da inter-relação desses com o espaço sociocultural do qual são oriundos.

Maurice Tardif (2012) defende a ideia de que devemos levar em conta o conhecimento do trabalho dos professores, seus saberes cotidianos, pois desta maneira podemos descontruir a ideia tradicional de que os professores são apenas transmissores de saberes produzidos por outros grupos, valorizando assim a subjetividade dos mesmos no processo de investigação. Desta forma, é possível pensar uma formação docente mais consequente e também mais próxima da nossa realidade. Segundo esse autor, a pesquisa universitária deve parar de ver os professores de profissão como objetos de pesquisa e passar a considerá-los como sujeitos do conhecimento.

Do ponto de vista da abordagem do problema tratou-se de uma pesquisa qualitativa considerando-a como o caminho que melhor se adequava ao projeto, pois, segundo Minayo:

A abordagem qualitativa trabalha com o universo dos significados, motivos, aspirações, crenças, valores e atitudes. Esse conjunto de fenômenos humanos é entendido aqui como parte da realidade social, pois o ser humano se distingue não só por agir, mas por pensar sobre o que faz e por interpretar suas ações dentro e a partir da realidade vivida e partilhada com seus semelhantes (MINAYO, 2010, p. 21).

A pesquisa de abordagem qualitativa permite que se trabalhe com a subjetividade do sujeito-objeto da pesquisa, isso é essencial para análise das 
narrativas. O método utilizado foi o (auto) biográfico, através da escuta das narrativas de vida da professora entrevistada, para poder conhecer melhor seu itinerário escolar, tomando por base a pesquisa do tipo etnográfico. Segundo Marli E. D. A. de André, “[...] uma característica da etnografia é a preocupação com o significado, com a maneira própria com que as pessoas veem a si mesmas, as suas experiências e o mundo que as cerca" (ANDRÉ, 2011, p. 25).

Christine Delory-Momberger defende que “as práticas das histórias de vida em formação repousam sobre a ideia da apropriação de sua história pelo indivíduo que faz a narrativa de sua vida" (DELORY-MOMBERGER, 2008, p. 16). Partindo desse pressuposto, acredito na relevância da pesquisa aqui apresentada tanto para o meio acadêmico quanto para a professora quilombola, pois a mesma teve a possibilidade de repensar sua (auto)formação e ressignificar suas experiências dentro e fora dos espaços formais de ensino.

Como a intenção da pesquisa Narrativas autobiográfica de uma professora negra quilombola: espaço de ressignificação do ser e do fazer docente era identificar a representação social da professora sobre a sua profissão assim como entender os sentidos que a docência assumia para ela em articulação com diferentes dimensões de sua vida (ser mulher, negra, quilombola), ressalto a importância deste estudo, pois acredito que, no processo de investigação, tive a possibilidade de repensar as minhas experiências pessoais e profissionais também pois ficou evidente que não podemos trabalhar com narrativas autobiográficas sem nos deixarmos interpelar pelas mesmas.

Nesse primeiro momento tentou-se ressaltar o papel das narrativas, das Histórias de Vida, no processo investigativo. Porém, a análise das fontes também será realizada à luz da crítica cultural. Por isso, refletiremos a partir de agora sobre as contribuições, do ponto de vista dos estudos culturais acerca da metodologia. Partiremos então do modelo cartográfico, ou rizomático que vem ganhando espaço no campo da Educação.

O modelo do rizoma é uma criação dos autores Gilles Deleuze e Félix Guattari em seu livro Mil Platôs em 1980, como segunda parte do Capitalismo e Esquizofrenia, rompendo com o historicismo do século XIX (DOSSE, 2010, p. 209). O livro é um tipo de cartografia das micropolíticas e que permitem restituir os modos de articulação entre os processos de subjetivação e os 
aparelhos institucionais, fazendo emergir a produtividade potencial dos grupos-sujeitos.

Para Dosse (2010), os autores já deixam claro desde o título que o termo platô dá a ideia de planície, zona plana de onde dificilmente saberíamos onde fica o começo e o fim, tampouco os limites.

Contudo, Mil Platôs não tem como referência direta a disciplina geográfica, mas tem como horizonte uma verdadeira física "no sentido da (meta)física bergsoniana, ou melhor, de geografia da phisis. [...] É uma maneira de relembrar a importância do acontecimento para sua filosofia, mas segundo uma lógica que não tem mais nada de cronológico nem de evolutivo (DOSSE, 2010, p. 210).

O Rizoma é um modelo descritivo adotado de algumas plantas cujos brotos podem ramificar-se em qualquer ponto, que é uma contraposição ao modelo histórico linear vigente. A relação desse modelo do rizoma com a produção do conhecimento parte do princípio que assim como no Rizoma que se contrapõe a um modelo binário ou totalitário uma vez que de qualquer parte da planta podem surgir novos brotos, assim também no campo epistemológico, seja necessário valorizar todas as contribuições teóricas não precisando necessariamente que as mesmas sigam linhas de pensamento lineares, como num modelo arbóreo tradicional onde tudo deriva de um mesmo centro, desconfigurando assim a importância da(s) diferença (s), da multiplicidade de olhares.

Partindo desse pressuposto a análise das narrativas de professores, pode buscar inspiração para compreender que a construção dos saberes não se dá de forma linear e que a própria vida narrada sob diferentes óticas, seja ela do ponto de vista profissional, da formação ou pessoal, pode "ser desmontável, conectável, reversível, modificável com várias entradas e saídas, com suas linhas de fuga [...]" assim como no rizoma (DELEUZE \& GUATTARI, 2004, p. 32).

As narrativas são fruto da memória, e a memória é a própria essência do psiquismo, segundo Derrida (2001, p. 185). Freud estudou os processos de arquivamento de informações no psiquismo humano. Como ficavam gravados os processos de percepção em memórias conscientes e inconscientes. (TELLES, 2002). Derrida questiona, em seu texto Mal de Arquivo, como seriam esses registros, os arquivos, numa era tecnocientífica 
como a que vivemos. Porém o que nos interessa do texto para a atual pesquisa, e o que nos chamou a atenção foi inicialmente as indagações sobre o próprio conceito de arquivo, que significa ao mesmo tempo, começo e comando.

Derrida mostra a dupla raiz da palavra arquivo, arkhê, que implica começo e comando (arconte, o que comanda). Esses significados linguísticos expõem uma verdade social e histórica - a relação entre o poder e o arquivo. É o poder quem detém o arquivo, é ele quem dispõe das informações, organizando uma história dentro de seus interesses, o que - evidentemente - tem decisivas consequências políticas (TELLES, 2002) ${ }^{2}$.

Derrida estabelece uma relação entre o que acontece na historiografia com o que acontece com a própria psicanálise. Tomando como base a obra de Freud e suas descobertas sobre o inconsciente, a autor questiona se, as nossas memórias também não passariam por um processo de negação, de repressões, consciente ou inconscientemente uma vez dado o poder institucional nas nossas vidas. A essa negação de elementos da memória de certos acontecimentos, ele chamará de Mal de Arquivo, o que para o autor, nos conduzirá a uma pulsão de morte ${ }^{3}$.

Essa percepção poderá contribuir muito para a análise das narrativas da professora, atentando para outro elemento trazido pelo autor Carlo Ginzburg, a importância dos detalhes presentes de maneira implícita no discurso da mesma, detalhes que muitas vezes, fogem da atenção do pesquisador, mas que podem estar intrinsecamente presente na linguagem, detalhes também aos quais precisamos dar atenção visto que nossa escuta é por vezes muito seletiva.

Em seu livro "Mitos, emblemas, sinais: morfologia e história," no capítulo intitulado “Sinais: raízes de um paradigma indiciário”, Ginzburg (1990) apresenta um convite a repensar diferentes formas de investigação. $\mathrm{O}$ autor se inspira no método de três figuras: o historiador Giovanni Morreli, o investigador Scherlok Holmes e o psicanalista Sigmund Freud.

\footnotetext{
${ }^{2}$ Disponivel em: www.polbr.med.br/ano02/psi0202.php.

3 "[...] a pulsão de morte seria denominada por Derrida como arquiviolítica, apagando então os traços inscritos e possibilitando que novas inscrições pudessem ser realizadas no arquivo". Ver o texto de Joel Birman Arquivo e Mal de Arquivo: uma leitura de Derrida sobre Freud, na PEPSIC, junho de 2008.
} 
Ginzburg critica as ciências sociais dizendo que as mesmas deixam muito a desejar em relação aos detalhes na pesquisa, e o autor toma como fonte de inspiração o método moreliano que ficou muito conhecido pelo "perfeccionismo" dos detalhes, que muitas vezes são renegados pelos pesquisadores. Segundo Morrelli,

[...] é preciso não se basear, como normalmente se faz, em características mais vistosas, portanto mais facilmente imitáveis, dos quadros: os olhos erguidos para o céu dos personagens de Perugino, o sorriso dos de Leonardo, e assim por diante. Pelo contrário, é necessário examinar os pormenores mais negligenciáveis, e menos influenciados pelas características da escola a que o pintor pertencia: os lóbulos das orelhas, as unhas, as formas dos dedos das mãos e dos pés (GINZBURG, 1990, p. 144).

Esse olhar moreliano sobre a investigação em Educação, por exemplo, nos faz perceber a necessidade de estarmos atentos a detalhes, presentes nos discursos dos professores, pois a própria linguagem às vezes, não dá conta de forma direta, de expressar aquilo que se almeja, sendo necessário que busquemos aquilo que está "escrito nas entrelinhas".

Associando Freud ao método moreliano, pode-se dizer que para o psicanalista, os ensaios de Morelli representaram um método investigativo centrado nos resíduos, sobre os dados marginais, considerados reveladores e esses dados eram muitas vezes, capazes de fornecer uma chave de compreensão de elementos triviais do espírito humano (GINZBURG, 1990 p. 146). Podemos fazer então um paralelo entre o pensamento de Derrida em Mal de Arquivo, onde o mesmo afirma que há muitas memórias "negadas" por causa do poder institucional e a necessidade de se buscar a aplicação do método moreliano, para se entender os mecanismos de força exercidos pelas instituições e as implicações das mesmas na vida do sujeito pesquisado, que negam essas memórias.

O método moreliano pode ser muito útil no momento em que o pesquisador analisa as entrevistas narrativas, pois há nas pessoas, como dito anteriormente, uma tendência natural à uma escuta seletiva ao invés de uma escuta sensível. Há um risco quando se seleciona as falas de alguém, ou se condiciona respostas esperadas para que as mesmas estejam em 
conformidade com crenças pré-concebidas destruindo assim a dimensão ética da pesquisa e as verdadeiras descobertas que a(s) pesquisa(s) possam revelar.

Outra contribuição dentre os autores da crítica cultural foi o escritor Giorgio Agamben. O autor começa seu texto "Infância e História: ensaio sobre a destruição da experiência", afirmando que o homem moderno foi expropriado de fazer e transmitir experiências. Segundo Agamben, a experiência tem o seu correlato não no conhecimento, mas na autoridade, ou seja, na palavra e no conto, e hoje ninguém mais parece dispor de autoridade suficiente para garantir uma experiência, e se dela dispõe, nem ao menos o aflora a ideia em fundamentar em uma experiência de autoridade (AGAMBEN, 2008, p. 21).

O projeto da ciência moderna, fortemente influenciado pelo pensamento cartesiano, buscou muito mais o experimento do que a experiência, valorizando assim as ciências exatas em detrimento das humanas, transpondo assim, a experiência para fora do homem (AGAMBEN, 2008).

A contribuição do pensamento de Agamben para a pesquisa com o projeto sobre histórias de vida de uma professora quilombola encontra-se, sobretudo, na valorização das experiências da professora que através dos seus relatos autobiográficos, passa a ser vista como sujeito da sua própria formação, sublinhando a importância dos seus saberes construídos dentro e fora dos ambientes formais de ensino. O trabalho com as narrativas, com as histórias de vida, nos faz valorizar as subjetividades, o que se contrapõe fortemente a um modelo cartesiano de pensar a investigação.

\section{Narrativas autobiográficas e as representações sociais}

A coleta de dados da pesquisa foi realizada através de entrevistas narrativas. Foram realizadas visitas ao Quilombo do Burí - Pedrão/Ba, à Escola Manoel Bellom, a escola primária da professora entrevistada, na época chamada de Escola 21 de Abril, em vista de conhecer o ambiente no qual a professora nasceu e cresceu e também foi visitada a Escola Municipal na qual a mesma estudou o ensino fundamental (o ginásio na época), e onde ela exerce hoje a função de Coordenadora Pedagógica.

Do ponto de vista teórico-metodológico fez-se uma escolha de começar as análises através da teoria das Representações Sociais, visto que 
muito daquilo que a professora expressou está atrelado a um conjunto de representações, sejam elas acerca da profissão docente, sejam elas em relação às suas identidades: negra, mulher, quilombola.

O criador do conceito de representações sociais foi Serge Moscovici em 1961, na França. Moscovici era psicólogo social e desenvolveu uma pesquisa de Doutorado querendo compreender como a Psicanálise era apreendida pelo senso comum, ou seja, pelos grupos populares, longe dos espaços acadêmicos e especializados. Na base da sua pesquisa o autor buscou compreender a relação entre os fenômenos sociais e psíquicos.

Moscovici baseou suas teorias nos trabalhos desenvolvidos por Emile Durkheim através do conceito de representação coletiva, na Teoria da Linguagem de Saussure e na Teoria das Representações Infantis de Piaget, além da Teoria do Desenvolvimento Cultural de Vygotsky. Como pode-se observar, a Teoria das Representações Sociais bebe tanto da Sociologia quanto da Antropologia e da Linguística (WERBA e OLIVEIRA, 2013). O autor era extremamente crítico das correntes positivista e formalista, pois segundo ele, essas teorias não davam conta de explicar a realidade e suas dimensões como a dimensão histórico-crítica (ALEXANDRE, 2004, p. 124).

Segundo Jodelet (2001, apud Marques e Musis, 2016): a representação social:

É uma forma de conhecimento, socialmente elaborada e partilhada, com um objetivo prático, e que contribui para a construção de uma realidade comum a um conjunto social. Igualmente designada como saber ingênuo, natural, esta forma de conhecimento é diferenciada, entre outras, do conhecimento científico. Entretanto, é tida como um objeto de estudo tão legítimo quanto este devido à sua importância na vida social e à elucidação possibilitadora dos processos cognitivos e das interações sociais.

Como foi dito anteriormente as representações sociais buscam uma relação entre os fenômenos sociais e psíquicos, entre o psicológico e o social, por isso elas se dão num conjunto de interações cotidianas, através das mais diversas interações sociais, através de conversas informais, das experiências educacionais assim como dos saberes populares transmitidos de geração em geração. 
Estudar as representações sociais é na visão de Oliveira e Werba (2013) “conhecer o modo como um grupo humano constrói um conjunto de saberes e expressam a identidade de um grupo social", por isso é de extrema importância partir dessas representações para compreender os elementos que estão presentes nas narrativas da professora entrevistada para a pesquisa e o conjunto de valores que contribuíram para a construção das suas crenças, sejam elas afetivas, míticas ou religiosas.

Para melhor elucidar esses conceitos extraímos algumas falas da professora pesquisada. Aqui a chamaremos de Dandara. Ela nasceu no dia 03 de novembro de 1968, filha de lavradores, seus seu pais tiveram sete filhos e adotou mais um. Bisneta de um escravo, Manoel Bellom, foi a precursora na busca pelo reconhecimento da sua comunidade como Comunidade Quilombola. Aos 50 anos de idade Dandara já soma 31 anos de vida profissional enquanto professora primaria, casada e com dois filhos atualmente residindo no quilombo e trabalha como coordenadora pedagógica na escola Luiz Viana no município de Pedrão.

Começaremos apresentando as memórias de Dandara sobre sua formação na escola primária.

Aos 8 anos eu comecei a estudar aqui na escola daqui da comunidade mesmo que é a Escola 21 de Abril. Mas eu comecei a estudar nessa escola, não porque minha mãe queria, e como meus irmãos estudavam lá na sede na escola de professora Maria Lima, então minha mãe queria que eu fosse para essa escola e aí eu comecei a chorar muito, devido ao que alguns dos meus irmãos falavam em relação ao que acontecia nesta escola, que tinha um quarto escuro e que tomava palmadas e bolos, então passando o primeiro dia pra ir pra escola na sede a gente tinha que ir de pé, então a professora Joana que eu considero como a minha primeira professora na escola rural, aí ela vendo todo meu desespero, pediu a minha mãe que me deixasse estudando aí com ela, e só tinha de aluna no caso nessa idade para essa serie que, que era alfabetização, só tinha eu.

As primeiras memórias de Dandara não remetiam a algo positivo. A escola distante da sua realidade mesmo sendo um lugar onde seus irmãos estudavam representava um lugar de disciplina muito mais que um espaço comunitário. Na sua fala isso é representado através das imagens do quarto escuro e das situações de repressão como palmadas e bolos. É somente a 
partir da iniciativa de uma professora chamada Joana que Dandara começa a estudar próximo de casa sob os cuidados dessa professora. Nas suas memórias a professora sempre é representada como alguém que cuida e que dispensa carinho aos alunos.

Segundo Arroyo (2011) os professores de educação infantil carregam uma imagem difusa, pouco profissional. Para ilustrar isso, o autor exemplifica fazendo menção a uma professora inconformada com os requisitos exigidos para trabalhar no maternal: simpatia, boa aparência, carinhosa no cuidado das crianças e amável no trato com as famílias. Segundo o autor a professora das primeiras séries da educação fundamental carrega outra imagem social mais definida, porém ainda pouco profissional, ela precisa ser dominante, ser competente no ensino das primeiras letras, mas sobretudo ser carinhosa, cuidadosa e dedicada, "ser professora ou professor é carregar uma imagem socialmente construída” (ARROYO, 2011, p. 30).

Quando questionada sobre as memórias acerca de seus professores e as representações que a mesma carrega sobre a docência, percebe-se uma ligação da imagem do professor, às imagens apresentadas no século XIX na Europa: dois elementos aparecem de maneira intrínseca, vocação e sacerdócio.

Eu acho que o bom profissional, ou seja, o bom professor,
é aquele que procura entender que seus alunos precisam
adquirir conhecimento, sim, precisa, mas também que
deve ser um profissional tolerante, tratar seus alunos
com carinho, e acima de tudo cumprir com suas
responsabilidades enquanto professor, se ele tá em sala,
ele está em docência, ele precisa cumprir com suas
responsabilidades, não visar assim o seu salário que vai
receber no final do mês, isso importa também, mas pra
isso também, eu preciso me mostrar um bom profissional,
não só porque eu vou receber meu salário no final do mês,
mas preciso cumprir com meus deveres, porque a partir
do momento que eu assumi uma docência, eu preciso ser
responsável pelos meus alunos, para o sucesso deles, eu
preciso cumprir, com meus deveres enquanto professor,
não é? Eu vejo assim, dessa forma, que o bom profissional.

Esse trecho da entrevista pode explicitar alguns adjetivos usados pela professora para qualificar um bom professor: interessado, profissional impecável, tolerante, carinhoso, responsável. Acrescido a essa noção de entrega, ainda pesa sobre essa imagem a ideia de não exercer a profissão 
somente visando o salário no fim do mês. Isso nos remete às representações sociais do professor no século XVIII em Portugal. Antonio Nóvoa (1989) relata que "O recurso aos conceitos de vocação e de sacerdócio para definir a profissão docente é bem sintomático das referências religiosas de que continua impregnada em pleno século xx", pois naquela época a educação estava aos cuidados da Igreja que exercia sobre os professores um controle político e ideológico. Posteriormente esse controle será feito através do Estado.

Essas questões são levantadas aqui porque elas corroboram com as ideias de Tardif apresentadas anteriormente acerca das representações sociais do professor da educação infantil. Uma visão um tanto romantizada e, poderíamos dizer, pouco profissional. Se o professor no século XVIII aparece como um sacerdote vocacionado ao serviço dos demais, hoje se confunde com as figuras materna ou paterna.

Estar na escola, já era um grande desafio para Dandara, por conta das questões financeiras. Aliado a tais dificuldades e, mesmo estando no quarto município mais negro do Brasil, ela vai enfrentar um outro problema sério: a discriminação e o preconceito por causa do seu cabelo:

[...]Nesse processo de discriminação que agente sofria antes e que nem se sabia, mas a gente não tinha muito conhecimento do que era preconceito, do que era bullying, que era isso, que era injuria racial, mas como eu tinha, quando eu era pequena, meu cabelo, é, ele era muito cheio, grande e crespo, crespo mesmo de terminar de desembaraçar ele agora e daqui a pouco ele estava todo ninhado, aí minha mãe tinha aquela coisa, de fazer aquele penteado, aquelas tranças que vinha aqui na frente, que ela chamava de trança nagô, e então quando eu chegava na escola na sede os meninos me chamava de vaca banana, diziam "é lá vem a vaca banana", então eu falei, eu sempre chegava em casa e dizia assim "um dia eu vou melhorar meu cabelo, um dia eu vou melhorar para ninguém me chamar assim". E aí, é, quando eu com mais ou menos 11 anos, aí teve uma pessoa daqui teve um casal ali, né? Que se organizaram para se casar e aí me chamaram para ser a daminha, e aí eu falei com minha mãe "ta na hora agora de coisar meu cabelo, com meu cabelo desse jeito eu não vou" aí pegou o ferro, aquele ferro que esquenta em brasa, alisou meu cabelo e aí o cabelo ficou todo lindo, todo grande, daí pra cá pronto, essa minha condição do cabelo duro e crespo não me 
pertencia mais. Hoje eu sinto saudades do meu cabelo crespo, muitas saudades.

A autora Nilma Lino Gomes escreveu um artigo chamado Educação, identidade negra e formação de professores/as: um olhar sobre o corpo negro e o cabelo crespo, onde a mesma discute as particularidades e as possíveis relações entre os enunciados supracitados, salientando que a escola infelizmente nem sempre é lembrada como uma instituição em que o negro e seu padrão estético são percebidos de maneira positiva (GOMES, 2003).

Nessa pesquisa Gomes revela que no processo da construção da identidade o corpo pode ser considerado como um suporte da identidade negra e o cabelo crespo como um forte ícone identitário. Pode-se observar através da linguagem popular que o cabelo crespo sempre foi tomado de uma conotação negativa, para isso foram criados varias terminologias ainda hoje presentes como cabelo duro, cabelo ruim, cabelo de Bombril, cabelo pixaim.

Vale salientar que as marcas no corpo e no cabelo sempre representaram identidades dentro das culturas indígenas e africanas, ou seja, não se trata somente de uma questão estética mas representa-se uma identidade cultural e uma memória ancestral. Diante da experiência de Dandara podemos perguntar em que medida a escola, a sala de aula vem contribuindo para a negação ou o fortalecimento de determinados estereótipos acerca do corpo negro? Estão os professores preparados para lidar com experiências de diversidade cultural? (GOMES, 2003). O corpo é um símbolo explorado nas relações de poder e de dominação, para classificar e hierarquizar grupos diferentes e o cabelo é um dos elementos mais visíveis e destacados do corpo. A partir da implementação da lei 10639/03 tenta-se construir representações sociais mais positivas sobre o negro, apesar de haver ainda muitas resistências, isso indica a necessidade de criar espaços de debate tanto dentro quanto fora dos espaços formais de ensino.

O terceiro elemento dessa seção destaca a forma como os meninos e as meninas eram criados, educados. Destacar que gênero sempre foi um elemento utilizado para legitimar o poder.

[...]A criação se tinha, se tinha diferença entre a criação de meninos e meninas, tinha porque minha mãe dizia que a gente tinha que ficar em casa, as meninas tinha sempre que ficar em casa pra lavar os pratos, para varrer a casa, né? A gente não podia sair, os meninos podia ir pra festa, a 
gente não, só ia se ela fosse, ou se meu pai. Mas sempre que ela dava algum vacilo assim, eu tava no meio dos meninos brincando bola, brincando gude, porque meus irmãos quando eles, eles iam brincar na casa de meus primos, não é? Com primos aqui, então eles levavam a gente, mas la eles ficavam de olho, não deixavam que ninguém mexia na gente. Então era uma proteção, que até hoje eles tem também, que até hoje eles tem essa proteção com a gente, não pode ver ninguém falar nada, eu tenho um irmão mesmo, meu irmão mais velho que não pode ver ninguem falar nada, se falar, ave maria ele já chega aqui "ói falaram isso de você, bora procurar resolver" ele é todo assim. Mas ele davam proteção a gente, mas os pais não deixavam não. Pra quando ia pras rezas, que aqui tinha muitas rezas, todo sábado tinha uma reza, então a gente tinha que ir a com a rezadeira, se minha mãe não fosse, a gente tinha que ir com ela e voltar com ela. Mesmo que tivesse festa, a gente não podia ficar. Se ela não dissesse que a rezadeira ficava, a gente ficava, falou "vamos embora", todo mundo ia embora, ninguém ficava. Isso não acontecia só com a gente, comigo, e meus irmãos não, acontecia também com outras meninas, com outras famílias. Tinha aquela coisa "menina tem que fica no lugar menina e menino brincar junto com menino", a gente não brincava assim muito junto não, só quando elas vacilavam.

No texto $A$ representação social da mulher: história, avanços $e$ retrocessos, pode-se constatar como os discursos acerca do papel da mulher na sociedade são construídos e quais elementos e instituições vão fundamentar tais discursos. A autora do texto Fabiane Natália Souza Pinto (2015) nos diz que se hoje em dia a mulher possui liberdade para fazer escolhas, sejam elas pessoais afetivas ou profissionais, foi necessário atravessar um extenso percurso de transformação histórico cultural.

A nossa sociedade ocidental marcada pelos valores judaico-cristãos é, na sua base, patriarcal e dois elementos contribuíram para uma representação social da mulher na mesma: a cultura e a religião. Na experiência de Dandara pode-se constatar isso, quando a mesma diz que enquanto os meninos podiam tudo fazer, às meninas era dado o direito de participar das atividades somente sob supervisão dos outros.

Em relação à religião Pinto (2015) nos diz que a mulher não teve controle de si inclusive quando se tratava dos seus sentimentos e de sua sexualidade. Sempre submissa, ela precisava despertar os interesses dos 
homens por elas, porém havia necessidade primeiramente de que essa vontade fosse submetida à de um outro homem: seu pai (ARAUJO, 2012, apud, PINTO,2015).

Durante a Idade Média e no Período Colonial a Igreja Católica construiu a imagem da mulher perfeita, que era a Virgem Maria, portanto havia uma necessidade de controle das mulheres como uma forma de coibir o pecado, por isso cria-se aos poucos uma idealização da mulher para casar. A honra feminina precisava ser defendida a todo custo. Quando a mulher era solteira ela deveria ser virgem e se resolvessem casar, as mesmas deveriam dedicar-se a ser boa mãe e boa esposa. Nesse contexto, segundo Perrot (2008) "a virgindade feminina conferia um alto valor conduzindo as famílias a vigiar e controlar suas filhas em vista de lucros familiares".

A imagem da maternidade era algo sagrado para a mulher, pois permitia que as mulheres fossem relacionadas à figura sagrada de Maria, a mãe de Jesus e permitia a mulher mãe de produzir algo, além do pecado. As mulheres eram educadas para servir e a medicina dessa época desenvolveu-se em vista dos cuidados das enfermidades do útero, chamado curiosamente de madre (DEL PRIORE, 2012). Assim como aconteceram todos os cuidados com as mulheres no período colonial ainda hoje de maneira sutil valores ideológicos e morais sobre o comportamento feminino são encontrados em nosso meio.

Esse controle do feminino por vezes internalizado pelas meninas, às conduzem a viver constantemente tentando agradar a todos. A "boa moça de família", como se escuta ainda hoje vai criando o que Michel Foucault chamará de corpos dóceis. Nos relatos de Dandara, fica nítido a necessidade de "ser uma pessoa exemplar".

[...]E assim eu não tive muito, muita problemática não porque eu sempre fui uma aluna centrada, muito exemplar. Prova disso, que na mesma escola que eu me formei, voltei a ensinar nessa escola, então pela, pelo aquele conhecimento, pela aquela, responsabilidade que eu tinha com os estudos, nunca fui reprovada nunca, nunca foi pra uma recuperação, nunca fiz uma recuperação. Agora me marcou muito quando eu cheguei no ensino médio, eu tava no ensino médio, que aí um professor, professor Luiz, como era só sete no terceiro ano, aí teve seis alunos que perderam na matéria de educação física e aí ele não deu o resultado de ninguém e botou todo mundo pra fazer a recuperação. Eu aí fiquei a 
noite toda estudando com os pés dentro de uma bacia de agua. Toda hora minha mãe acordava e me chamava, e eu lá estudando, quase que pego um resfriado...

Pra não dar sono, eu ficava esfregando os pés no outro pra poder não dar sono, pra poder ficar acordada estudando. Aí peguei estudei, cheguei lá, fiz essa recuperação, mas depois ele chamou todo mundo, e disse "ói Angélica, você não precisava fazer a recuperação não, mas como eram sete, pros outros não fazer sozinho..." então eu quase que fui em cima dele mesmo, com muita raiva porque ele fez isso, porque eu perdi a noite, quase fiquei sem precisar fazer uma recuperação. Mas só foi esse trauma que teve, superei, mas, quando eu encontrava com ele na rua, não gostava nem de olhar pra cara, né? Porque ele fez isso comigo, mas depois eu superei, porque de certa forma serviu também pra eu estudar mais um pouquinho.

O poder disciplinar apresentado por Michel Foucault em seu livro Vigiar e Punir (2010) permite compreender como, de maneira (in)consciente vários mecanismos institucionais corroboram para o controle dos corpos. $\mathrm{O}$ autor apresenta como as instituições sociais como a família, o quartel, a fábrica, a escola e o hospital se utilizam desse poder em vista do controle social.

Foucault explica que nos séculos XVII e XVIII, havia as Festas de Suplício nas quais haviam punições realizadas publicamente, repressões sobre os corpos condenados com o intuito de manter o controle da desordem social. Essas práticas (tortura, esquartejamento, amputação, etc.) vão perdendo força no século seguinte e as formas de controle vão ser redimensionadas.

Mas, o que acontece uma vez que se extingue a repressão social presente nas Festas de Suplício? Como será realizado o "controle social" uma vez que as pessoas precisam temer o crime para que a sociedade não se transforme num caos? O século XIX vai desenvolver o controle sobre os corpos em vista de obter aptidões e qualificações para execução do trabalho. Desenvolve-se nesse momento uma visão do corpo como um bem privado, e a liberdade ganha uma conotação de direito dos indivíduos.

Se por um lado não há mais os carrascos presentes nas festas de suplício, os mesmos serão substituídos por pessoas que exercem outras funções sociais como os guardas, os médicos, os psicólogos e até mesmo os educadores. Ou seja, o poder disciplinar toma outras formas e dimensões, não 
age mais através da violência dos corpos mas, apresenta-se aqui de forma simbólica, para relembrar a expressão violência simbólica de Pierre Bourdieu.

Segundo Bourdieu (2009), em seu livro "A Reprodução", os seres humanos possuem quatro tipos de capitais: o econômico, o social, o cultural e o simbólico. O capital simbólico está ligado ao prestígio, ao reconhecimento e através dele determinadas diferenças de poder são definidas socialmente. A violência simbólica acontece dentro das relações sociais com o consentimento das partes envolvidas. Um exemplo desse tipo de violência se dá no campo da linguagem, na forma como as pessoas se referem através de estereótipos contra negros, nordestinos, mulheres, etc.

O controle social sobre os corpos dar-se-á através de métodos que vão permitir de forma minuciosa a submissão dos seres humanos, dos indivíduos dentro de uma relação que Foucault chamará de "relação docilidade-utilidade". Esses métodos são as disciplinas, que se tornaram no século XVII e XVIII fórmulas gerais de dominação. Para o autor disciplina aqui é diferente de escravidão, é diferente de domesticidade, diferente de vassalidade assim como é diferente de ascetismo.

O momento histórico das disciplinas é o momento em que
nasce uma arte do corpo humano, que visa não
unicamente o aumento de suas habilidades, nem
tampouco aprofundar sua sujeição, mas a formação de
uma relação que no mesmo mecanismo o torna tanto
mais obediente quanto é mais útil, e inversamente.
Forma-se então uma política de coerções que são um
trabalho sobre o corpo, uma manipulação calculada de
seus elementos, de seus gestos, de seus comportamentos
(FOUCAULT, 2010, p. 133).

Se tomarmos como exemplo o ambiente escolar, podemos perceber que as práticas pedagógicas, em grande parte, sempre foram formas de controle disciplinar. Abandonou-se as práticas de castigo físico muito utilizadas no passado como a palmatória, ajoelhar-se no milho entre tantas outras, para realizar o controle dos alunos fazendo uso da hierarquia, das avaliações que por vezes tomam até forma de vinganças, ameaças de suspensão das aulas. Para Foucault (2010, p. 164), “o sucesso do poder disciplinar se deve sem dúvida ao uso de instrumentos simples: o olhar hierárquico, a sanção normalizadora e sua combinação num procedimento que lhe é específico: o exame." 
O objetivo de inserir essa seção acerca dos corpos dóceis na análise das narrativas autobiográficas da professora é para poder mostrar como as pessoas tornam-se esses corpos dóceis, corpos disciplinados e através da pedagogia empregada em sala de aula pode-se observar o quanto a Escola ainda perpetua práticas de controle disciplinar, buscando fabricar corpos obedientes que buscam muito mais agradar, sem contestação alguma, deixando-se simplesmente instruir como modelo de comportamento exemplar.

\section{Considerações finais}

O objetivo da pesquisa foi demonstrar a importância das narrativas autobiográficas na formação docente. Pode-se constatar que através das narrativas podemos nos reinventar pois, nos tornamos autores e atores da nossa própria história e da nossa (auto)formação, e que através do método autobiográfico, os professores deixam de ser objeto de pesquisa e passam a ser sujeitos do conhecimento, e que há uma necessidade de respeitar os saberes de referência dos professores construídos dentro e fora dos espaços formais de ensino.

Através da análise das narrativas, podemos evidenciar que a escola ainda permanece como um lugar onde as diferenças não são respeitadas, onde as representações sociais de gênero, raça, são internalizadas desde muito cedo e legitimadas por ideologias racistas e patriarcais e que não existe uma preocupação por parte das autoridades políticas de uma mudança, tornando urgente criar espaços de partilha, de discussões para que se possa assim desnaturalizar as desigualdades.

\section{Referências}

AGAMBEN, Giorgio. Infância e história: destruição da experiência e origem da história. Belo Horizonte: Editora UFMG, 2005.

ALEXANDRE, Marcos. Representação social: uma genealogia do conceito. Comum. Rio de Janeiro - vol. 10 - n.23 - p. 122-138 - julho/dezembro, 2004.

AMADO, J. (Org.) Usos \& abusos da história oral. Rio de Janeiro: Editora da Fundação Getúlio Vargas, 1996.

ANDRÉ, Marli E.A. de. Etnografia da prática escolar. 18. ed. Campinas, SP: Papirus, 2011. (versão digital) 
ARROYO, Miguel. Ofício de Mestre: imagens e autoimagens. 13 ed. Petrópolis, RJ: Vozes, 2011.

BOSI, Écleia. A pesquisa em memória social. Revista Psicologia USP, v. 4, São Paulo, 1993, p. 277-284.

BOURDIEU, P; PASSERON, Jean-Claude. A reprodução: elementos para uma teoria dos sistemas de ensino. Petrópolis: Vozes, 2002.

CHARTIER, R. A visão do historiador modernista. In: FERREIRA, M. e DELEUZE, Gilles; GUATTARI, Felix. Introdução: Rizoma. In: Mil platôs. capitalismo e esquizofrenia. Trad. Ana Lúcia Oliveira. Rio de Janeiro: Editora 34, 1995, p. 7-37.

CRUZ, Maria de Fátima Berenice da; REIS, Iramayre Cássia Ribeiro. LEI 10.639/2003: pela descolonização da prática pedagógica docente. Revista Fórum Identidades. Itabaiana:

GEPIADDE, Ano 7, volume 14| jul./dez. de 2013. ISSN: 1982-3916.

DELORY-MOMBERGER, Christine. Biografia e educação: figuras do indivíduo projeto. Trad. Maria da Conceição Passeggi, João Gomes da Silva Neto e Luis Passegi. Natal, RN: EDUFRN; São Paulo: Paulus, 2008.

DERRIDA, Jacques. Mal de arquivo: uma impressão freudiana. Trad. Claudia de Moraes Rego. Rio de Janeiro: Relume Dumará, 2001.

DOMINICÉ, Pierre. Prefácio. In: Biografia e Educação: Figuras do indivíduoprojeto. Natal: EDUFRN; São Paulo: Paulus, 2008.

DOSSE, François. Gilles Deleuze e Felix Guattari: biografia cruzada. Porto Alegre: Artmed, 2010.

FOUCAULT, M. Vigiar e Punir: uma história da violência nas prisões. Petrópolis: Vozes, 2010.

FOUCAULT, Michel. A ordem do discurso. São Paulo: Loyola, 1996.

GINZBURG, Carlo. Sinais: raízes de um paradigma indiciário. In: Mitos, emblemas, sinais: morfologia e história. São Paulo: Companhia das Letras, 1990.

GOMES, N. L. Educação, Identidade Negra e Formação de Professores/as: um olhar sobre o corpo negro e o cabelo crespo. Educação e Pesquisa, São Paulo, v.29, n. 1, pp 167-182, jan./jul. 2003.

GOMES, Nilma Lino. Educação, identidade negra e formação de professores/as: um olhar sobre o corpo negro e o cabelo crespo. Revista Educação e Pesquisa. São Paulo, v.29, n.1, p. 167-182, jan/jun, 20013.

GOMES, Nilma Lino. Intelectuais negros e produção do conhecimento: algumas reflexões sobre a realidade brasileira. In: SÁNTOS, Boaventura de Sousa. Epistemologias do Sul. Coimbra: Edições Almedina, 2009. 419-441. 
HALBWACHS, Maurice. A memória coletiva. São Paulo: Centauro, 1993.

JOSSO, Marie-Christine. Da formação do sujeito ao sujeito da formação. In: LARKIN, Elisa. O Brasil e a confecção do branco Virtual. In: O sortilégio da cor: identidade, raça e gênero no Brasil. São Paulo: Selo Negro, 2003.

JOSSO, Marie-Christine. Experiências de vida e formação. São Paulo: Cortez, 2004.

LOBATO, Vivian da Silva. Educação, Memória e História: possíveis enlaces. Revistas Margens Interdisciplinar. v. 8, n. 10. 2014.

MINAYO, Maria Cecília de Souza (Org.). Pesquisa Social: teoria, método e criatividade. 29. ed. Petropólis, RJ: Vozes, 2010.

NÓVOA, A. Vida de Professores. Porto: Porto Editora, 2006.

NOVOA, António. Diz-me como ensinas e dir-te-ei quem és e vice-versa. In: $A$ pesquisa em educação e as transformações do conhecimento. 4. ed. Campinas, SP: Papirus, 2004.

NOVOA, Antonio. Profissão: Professor. Reflexões Históricas e Sociológicas. Análise Psicológica. 1-2-3, (VII), 435-456, 1989.

NOVOA, António; FINGER, Mathias. O método (auto)biográfico e a formação do sujeito. Lisboa: MS/DRHS/CFAP, 1988.

OLIVEIRA, F.O; WERBA, G.C. Representações sociais. In.: JACQUES, M.G.C et al. Psicologia Social Contemporânea. Petrópolis: Vozes, 2013.

ROBINOVICH, Elaine Pedreira. Infância e história: destruição da experiência e origem da história. Revista Brasileira de Crescimento e Desenvolvimento Humano. 2005; 15: 119-123.

SOUZA, Elizeu Clementino de. O conhecimento de si: Estágio e narrativas de formação de professores. Rio de Janeiro: DP\&A; Salvador, BA: UNEB, 2006.

SOUZA, Elizeu Clementino de. Memoriais autobiográficos, profissionalização docente e identidade: histórias de vida e formação na pós-graduação. In. PASSEGGI, M.C.; BARBOSA, T.M. (Org.) Memórias, Memoriais: pesquisa e formação docente. Natal: EDUFRN; São Paulo: PAULUS, 2008. Pp 119-133.

SOUZA, Elizeu Clementino de. MIGNOT, Ana Chrystina Venancio (Org.). Histórias de vida e formação de professores. Rio de Janeiro: FAPERJ/QUARTET, 2008.

TARDIF, Maurice. Saberes docentes e formação profissional. 13 ed. Petrópolis, RJ: Vozes, 2006.

TELLES, Sergio. Mal de arquivo: as vicissitudes da memória segundo Derrida. Disponível em: TELLES, Sergio. Mal de arauivo: as vicissitudes da memória seeundo Derrida. Disponível em: www.polbr.med.br/ano02/psi0202.php. Acesso em 09.09.2017. 
Recebido em 29 de abril de 2019.

Aceito em 30 de maio de 2019. 